\title{
Haematological and fibrinolytic status of Nigerian women with post-partum haemorrhage
}

\author{
Ian Roberts ${ }^{1 *} \mathbb{D}$, Haleema Shakur ${ }^{1}$, Bukola Fawole ${ }^{2}$, Modupe Kuti $^{3}$, Oladapo Olayemi ${ }^{4}$, Adenike Bello ${ }^{4}$, \\ Olayinka Ogunbode ${ }^{4}$, Taiwo Kotila ${ }^{5}$, Chris O. Aimakhu ${ }^{4}$, Tolulase Olutogun ${ }^{5}$, Beverley J. Hunt ${ }^{6}$ and Sumaya Huque ${ }^{1}$
}

\begin{abstract}
Background: Early treatment with tranexamic acid reduces deaths due to bleeding after post-partum haemorrhage. We report the prevalence of haematological, coagulation and fibrinolytic abnormalities in Nigerian women with postpartum haemorrhage.

Methods: We performed a secondary analysis of the WOMAN trial to assess laboratory data and rotational thromboelastometry (ROTEM) parameters in 167 women with postpartum haemorrhage treated at University College Hospital, Ibadan, Nigeria. We defined hyper-fibrinolysis as EXTEM maximum lysis (ML) > 15\% on ROTEM. We defined coagulopathy as EXTEM clot amplitude at $5 \mathrm{~min}(\mathrm{~A} 5)<40 \mathrm{~mm}$ or prothrombin ratio $>1.5$.

Results: Among the study cohort, 53 (40\%) women had severe anaemia (haemoglobin< $70 \mathrm{~g} / \mathrm{L}$ ) and 17 (13\%) women had severe thrombocytopenia (platelet count $<50 \times 10^{9} / \mathrm{L}$ ). Thirty-five women $(23 \%)$ had ROTEM evidence of hyper-fibrinolysis. Based on prothrombin ratio criteria, 16 (12\%) had coagulopathy. Based on EXTEM A5 criteria, 49 (34\%) had coagulopathy.

Conclusion: Our findings suggest that, based on a convenience sample of women from a large teaching hospital in Nigeria, hyper-fibrinolysis may commonly occur in postpartum haemorrhage. Further mechanistic studies are needed to examine hyper-fibrinolysis associated with postpartum haemorrhage. Findings from such studies may optimize treatment approaches for postpartum haemorrhage.
\end{abstract}

Trial registration: The Woman trial was registered: NCT00872469; ISRCTN76912190 (Registration date: 22/03/2012).

Keywords: Fibrinolysis, Coagulation, Postpartum haemorrhage

\section{Background}

Tranexamic acid (TXA) administration reduces death due to bleeding in trauma patients. Among patients treated within $3 \mathrm{~h}$ of injury, TXA reduces death due to bleeding by one third [1-3]. Early activation of fibrinolysis is common after serious injury and contributes to the coagulation abnormalities seen in bleeding trauma patients [4, 5]. Hypo-perfusion and tissue injury are thought to start the coagulopathy, although we do not understand the molecular pathways [6].

\footnotetext{
* Correspondence: lan.roberts@|shtm.ac.uk

${ }^{1}$ Clinical Trials Unit, London School of Hygiene and Tropical Medicine, Keppel Street, London WC1E 7HT, UK

Full list of author information is available at the end of the article
}

Results from the WOMAN trial, a large randomised trial conducted primarily in low and middle income countries, show that early tranexamic acid use reduces death due to bleeding after postpartum haemorrhage (PPH) [7]. This suggests that fibrinolysis is also an important pathophysiological mechanism in obstetric bleeding. However, whereas increased fibrinolysis is common in trauma, its association with PPH is less well known [8]. We report the prevalence of hyper-fibrinolysis in women with PPH in Nigeria.

\section{Methods}

The WOMAN trial was a randomised placebo controlled trial of the effect of tranexamic acid on death, hysterectomy and other surgical interventions in women 
with clinically diagnosed primary PPH [7]. Although the diagnosis was clinical, we specified that diagnosis of primary PPH could be based on an estimated blood loss of more than $500 \mathrm{~mL}$ after vaginal birth or $1000 \mathrm{~mL}$ after caesarean section, or any blood loss sufficient to compromise haemodynamic stability. The diagnosis of $\mathrm{PPH}$ could also be made using clinical judgement, independent of the volume of blood loss. We have described the methods in detail elsewhere [7]. We examined haematological (full blood count) and haemostatic parameters in a sample of 167 trial participants recruited at University College Hospital, Ibadan, Nigeria. A total of 309 women were recruited into the WOMAN trial at University College Hospital. Because of occasional equipment failures and lack of reagents the 167 (54\%) women included in the ETAC study were not a consecutive series. Although most of the recruited women delivered at University College Hospital, some patients were transferred from outlying health facilities after they had developed PPH because they required urgent medical support. In these women, blood loss was estimated based on the history and observed blood loss.

After completing consent procedures but before giving the trial treatment (TXA or placebo), we drew approximately $15 \mathrm{~mL}$ of venous blood and divided the sample into three vacutainer tubes. We collected one $5 \mathrm{~mL}$ sample in a tube containing potassium EDTA for full blood count analysis and two $4.5 \mathrm{~mL}$ samples in tubes containing $0.5 \mathrm{~mL}$ sodium citrate $(0.109 \mathrm{~mol} / \mathrm{L})$ for coagulation and rotational thromboelastometry. We used a five-parameter particle counter Sysmex KN analyser (Sysmex Corporation, Kobe, Japan) for the blood count analysis. Anaemia was defined according to the World Health Organisation definition of anaemia in pregnancy as a haemoglobin below $110 \mathrm{~g} / \mathrm{L}$ and below $70 \mathrm{~g} / \mathrm{L}$ for severe anaemia [9].

After centrifuging the blood at $3000 \mathrm{~g}$ for $20 \mathrm{~min}$, we measured prothrombin time (PT), normalised prothrombin ratio, activated partial thromboplastin time (aPTT), Clauss fibrinogen and D-dimers using a HumaClot Junior automated coagulation analyser. We measured ROTEM thromboelastometry parameters at $37^{\circ} \mathrm{C}$ using two of the four channels (EXTEM, APTEM) of the ROTEM coagulation analyser [TEM ${ }^{\circ}$, Munich, Germany]). In EXTEM, coagulation is initiated using a small amount of tissue factor and the development of the clot is expressed in numbers and as a trace. In APTEM, coagulation is initiated in the same way, but the addition of aprotinin or tranexamic acid in the reagent inhibits fibrinolysis in vitro. By comparing the two traces, the extent of fibrinolysis can be assessed. If the sample is hyper-fibrinolytic, the same degree of clot lysis seen in EXTEM is not present in APTEM (Fig. 1). The following ROTEM variables were examined from the EXTEM and APTEM traces (Fig. 2): Clotting time (CT) which corresponds to the time required to trigger the process of coagulation, amplitude of the clot at $5 \mathrm{~min}$ and $10 \mathrm{~min}$ (CA5 and CA10, respectively), maximum clot firmness (MCF), clot lysis at

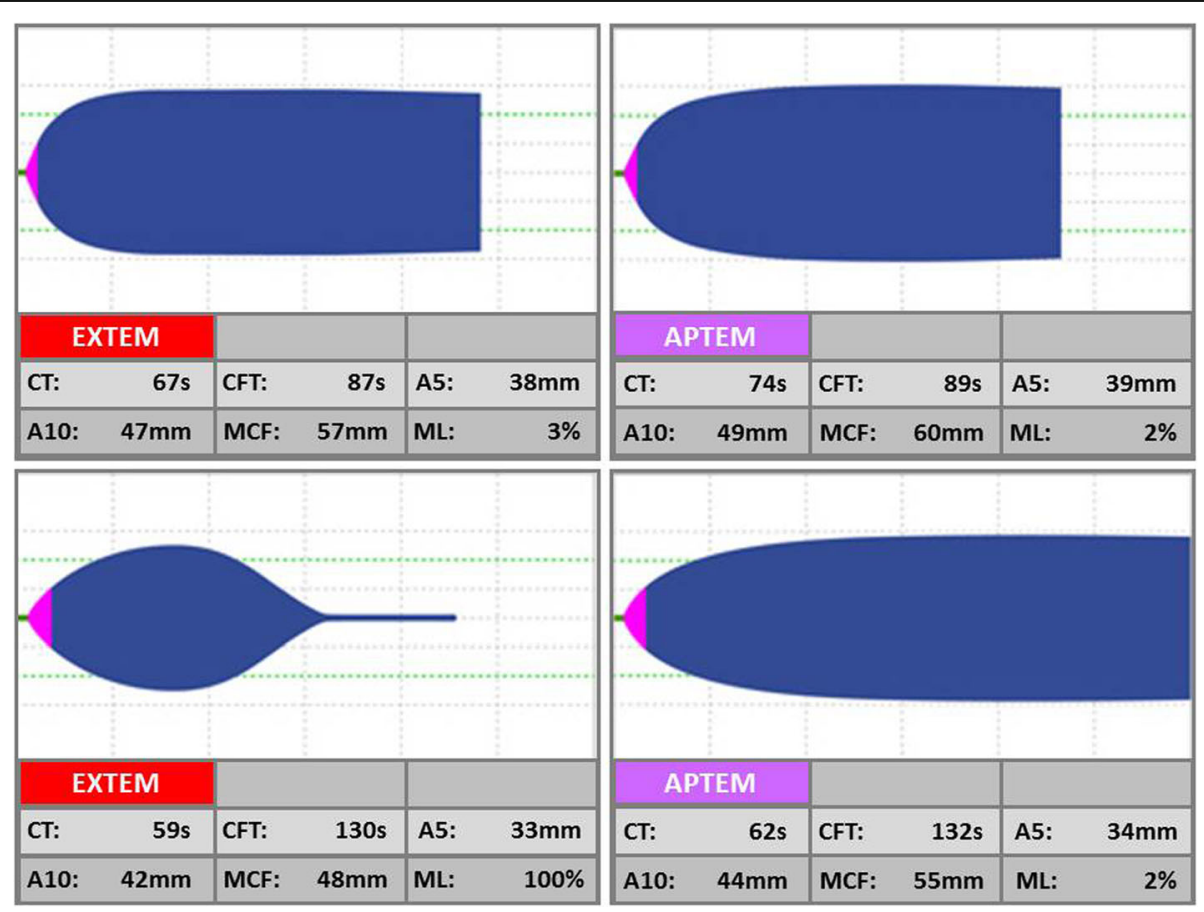

Fig. 1 ROTEM traces with (top) and without (bottom) hyper-fibrinolysis 


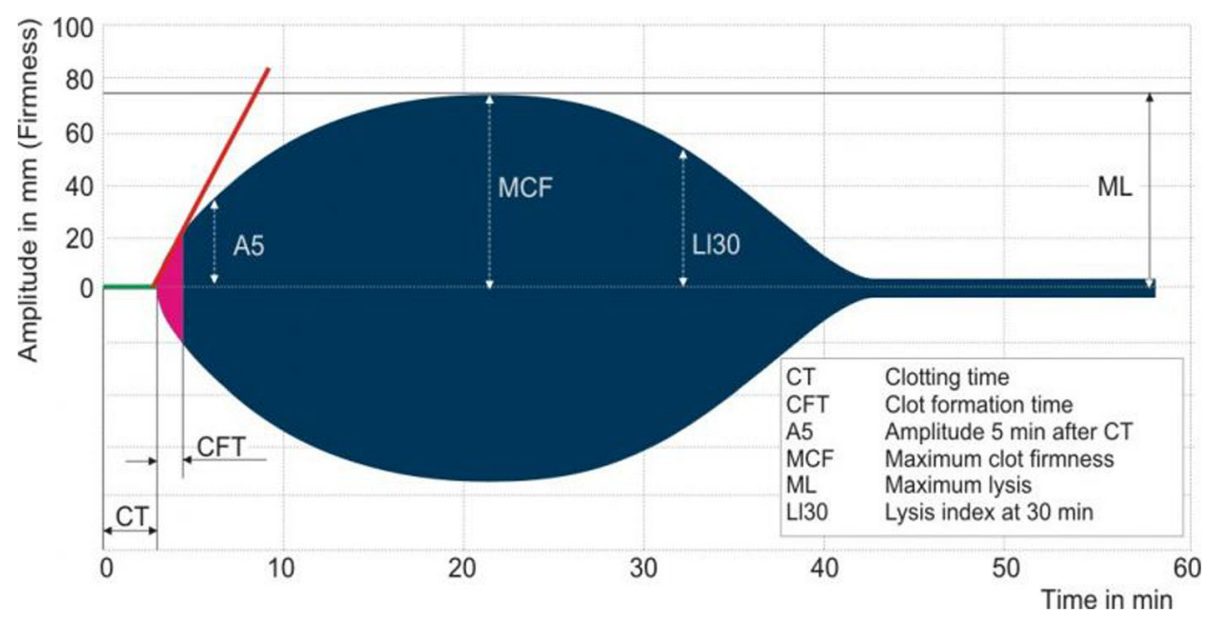

Fig. 2 Annotated trace showing ROTEM parameters

$30 \mathrm{~min}$ and $60 \mathrm{~min}$ (LI30 and LI60, respectively), and maximum lysis (ML). We stored the ROTEM reagents at $2-8{ }^{\circ} \mathrm{C}$ with temperature monitoring and we used in date reagents.

We conducted quality control (QC) analyses as per the manufacturer's recommendations. Before starting the study, TEM staff trained the Nigerian study team to use the ROTEM machine. We stored the ROTEM data on the machine with a backup after each analysis. We collected, cleaned and analysed the study data at the Clinical Trials Unit of the London School of Hygiene \& Tropical Medicine. Fibrinolysis was assessed as the amount of clot lysis on EXTEM (https://www.rotem.de/en/methodology/interpretation/). We defined hyper-fibrinolysis as ML $>15 \%$ on ROTEM EXTEM. This definition of hyper-fibrinolysis is provided by the manufacturer and is widely used in research studies [4]. Coagulopathy was defined as an EXTEM A5 $<40 \mathrm{~mm}$ or a prothrombin ratio $>1.5$. This A5 definition of coagulopathy was based on studies of the use of ROTEM to diagnose acute traumatic coagulopathy in which a $\mathrm{A} 5<40 \mathrm{~mm}$ predicted the receipt of massive blood transfusion in $73 \%$ of patients $[10,11]$. Normal ROTEM values for peri-partum Nigerian women have not been studied, so instead we have indicated the normal values from a study of 161 healthy peri-partum Dutch women [12].

\section{Results}

Table 1 shows the characteristics of the 167 women. One hundred and twenty eight women (77\%) gave birth in the hospital, whereas 39 (23\%) gave birth in other settings and were admitted after $\mathrm{PPH}$ onset. Seventeen (10\%) women received colloids during fluid resuscitation for $\mathrm{PPH}$ prior to sampling. The estimated mean blood loss at the time of randomisation and blood sampling was $1531 \mathrm{~mL}$. One hundred and eight (65\%) women lost more than $1000 \mathrm{~mL}$ of blood.

Table 2 shows the full blood count and haemostatic parameters. One hundred and sixteen (88\%) women were anaemic (haemoglobin < $110 \mathrm{~g} / \mathrm{L}$ ) and $53(40 \%)$ were severely anaemic (haemoglobin $<70 \mathrm{~g} / \mathrm{L}$ ) at the time of sampling. Thirty eight women (33\%) had a microcytic picture (defined as an mean corpuscular volume $<80 \mathrm{fl}$ ), although there was no further investigation to discover if this was due to iron deficiency or thalassemia traits or both. Twenty-six women (21\%) were lymphopenic (lymphocyte count $\left.<1 \times 10^{9} / \mathrm{L}\right)$. Forty-one $(32 \%)$ women had thrombocytopenia (platelet count $<100 \times$ $\left.10^{9} / \mathrm{L}\right)$ and $17(13 \%)$ had severe thrombocytopenia (platelet count $<50 \times 10^{9} / \mathrm{L}$ ).

Thirty five women (23\%) had an EXTEM ML $>15 \%$. If defined as an EXTEM A5 $<40 \mathrm{~mm}$, coagulopathy was present in 49 (34\%) mothers. If defined as a prothrombin ratio $>1.5$, coagulopathy was present in $16(12 \%)$ mothers. Of the women with an EXTEM A5 $<40 \mathrm{~mm}, 72 \%$ had a platelet count less than 100. The mean and median CT were markedly different suggesting that there are outliers. Of the 151 women with data for EXTEM CT, 127 women had a CT $\leq 100,22$ women had a CT between 101 and 1000 and two women had CTs of 1814 and 3468. If the two women with $\mathrm{CT}>1000$ are excluded, the mean (SD) and median (IQR) clotting times were 93.6 (138.7) and 54 $(45,70)$ respectively. The median (IQR) for plasma fibrinogen levels were $6.6(3.2-12.3) \mathrm{g} / \mathrm{L}$.

Figure 3 shows the relationship between estimated blood loss and the coagulation parameters (maximal lysis and A5). There was no significant correlation between estimated blood loss and maximal lysis $(r=0.01$, $p=0.86$ ). There was a weak but statistically significant negative correlation between estimated blood loss and A5 $(r=-0.35, p<0.001)$. After excluding women transferred 
Table 1 Baseline characteristics of trial participants $(N=167)$

\begin{tabular}{|c|c|}
\hline & Count (\%) / Mean(SD) \\
\hline \multicolumn{2}{|l|}{ Age (years) } \\
\hline Mean (SD) & $31.9(5.6)$ \\
\hline Range & $18-46$ \\
\hline \multicolumn{2}{|l|}{ Time since delivery (hours) } \\
\hline$\leq 3$ & $103(61.7 \%)$ \\
\hline$>3$ & $64(38.3 \%)$ \\
\hline Mean (SD) & $4.2(5.4)$ \\
\hline \multicolumn{2}{|l|}{ Type of delivery } \\
\hline Vaginal & $80(47.9 \%)$ \\
\hline Caesarean section & $87(52.1 \%)$ \\
\hline \multicolumn{2}{|l|}{ Delivery in randomising hospital } \\
\hline Yes & $128(76.7 \%)$ \\
\hline No & $39(23.4 \%)$ \\
\hline \multicolumn{2}{|l|}{ Cause of haemorrhage } \\
\hline Uterine Atony & $74(44.3 \%)$ \\
\hline Surgical trauma/tears & $59(35.3 \%)$ \\
\hline Placenta praevia/accreta & $21(12.6 \%)$ \\
\hline Other & $12(7.2 \%)$ \\
\hline Unknown & $1(0.6 \%)$ \\
\hline \multicolumn{2}{|l|}{ Systolic blood pressure $(\mathrm{mm}(\mathrm{Hg})$} \\
\hline$<90$ & $31(18.6 \%)$ \\
\hline$\geq 90$ & $135(80.8 \%)$ \\
\hline Missing & $1(0.6 \%)$ \\
\hline Mean (SD) & $110(27)$ \\
\hline \multicolumn{2}{|c|}{ Estimated volume of blood loss (mL) } \\
\hline$\leq 1000$ & $59(35.3 \%)$ \\
\hline$>1000$ & $108(64.7 \%)$ \\
\hline Median (25th, 75th percentile) & $1200(1000,2000)$ \\
\hline Range & $500-5530$ \\
\hline \multicolumn{2}{|l|}{ Colloids given } \\
\hline Yes & $17(10.2 \%)$ \\
\hline No & 150 (89.8\%) \\
\hline
\end{tabular}

from outside health facilities, the results were essentially the same (Maximal Lysis $r=0.06, p=0.51$; A5 $r=-0.46$, $p<0.001)$.

\section{Discussion}

Although 99\% deaths from PPH occur in low and middle income countries, most of the research on the haemostatic abnormalities in $\mathrm{PPH}$ is from high income countries [13-15].

Among this cohort of women who received care at a Nigerian hospital for $\mathrm{PPH}$, nearly one quarter of women had findings suggestive of hyper-fibrinolysis (ML > 15\%).
This contrasts with studies in high-income settings where hyper-fibrinolysis is considered less common in $\mathrm{PPH}$ [14] de Lange et al. reported that 9\% of women after normal labour had ML of $>15 \%$ within $1 \mathrm{~h}$ of delivery of the placenta [12] with increased D-dimer levels. Older studies looking at peri-partum changes in fibrinolysis show increases in tissue plasminogen activator (t-PA) immediately after delivery, followed by increases in plasminogen activator inhibitor (PAI-1) [16, 17].

In patients with trauma, ROTEM appears to underestimate the prevalence of fibrinolytic activation compared with more sensitive measures such as plasminantiplasmin complexes [4]. Further studies are needed to examine which parameters are most sensitive in detecting fibrinolysis in obstetric bleeding. Although we did not find any correlation between estimated blood loss and fibrinolytic activity, inaccuracy in blood loss estimates could easily have obscured such an association. Indeed, evidence from the WOMAN trial that administration of tranexamic acid significantly reduces death due to bleeding and re-operation for bleeding, strongly suggests that fibrinolysis plays an important role in $\mathrm{PPH}$. Furthermore, a randomised trial conducted in France has shown that there is an early increase in D-dimers and plasmin-antiplasmin complexes in women with active PPH and that this increase is attenuated among women who received tranexamic acid [18].

Fibrinogen levels would be expected to fall with increased fibrinolysis due to increased consumption and fibrinogenolysis. However, despite the high prevalence of hyper-fibrinolysis, the fibrinogen levels appeared to be elevated. Compared to non-pregnant women, fibrinogen levels are increased in pregnancy reaching their peak in the third trimester [19]. Nevertheless, the fibrinogen levels seen in our study are higher than in studies in high income settings. This might be related to the effects of inflammation due to acute and chronic infections including HIV and their treatments [20]. The prevalence of HIV in Nigeria is $3 \%$ and it is notable that $21 \%$ of our sample were lymphopenic. Further studies in low and middle income countries are need to confirm or refute our results.

Many women were anaemic and the degree of anaemia suggests that many were anaemic before developing $\mathrm{PPH}$. Anaemia in Africa has multiple aetiologies including iron deficiency, functional iron deficiency (due infections such as malaria and HIV); genetic conditions such as sickle cell disease, thalassemia and glucose-6-phosphate dehydrogenase deficiency; parasitic infections leading to blood loss (e.g. hookworms); and drugs such as anti-retrovirals. Furthermore, due to the expansion of the plasma volume in pregnancy, haematocrit falls. Olatunbosun et al. found that $54 \%$ of women booking into an obstetric clinic in Uyo, Nigeria were anaemic, with most having evidence of 
Table 2 Haematological parameters of trial participants at baseline $(N=167)$

\begin{tabular}{|c|c|c|c|c|}
\hline & $n^{\mathrm{a}}$ & Mean (SD) / Count (\%) & $\begin{array}{l}\text { Median ( } 25 \text { th, } 75 \text { th } \\
\text { centile range) }\end{array}$ & Normal range ${ }^{b}$ \\
\hline \multicolumn{5}{|l|}{ Full Blood Count Variables } \\
\hline Red blood cell count $(\times 10 \wedge 12 / L)$ & 130 & $2.9(1.0)$ & $3.0(2.3,3.7)$ & $3.8-5.8$ \\
\hline Haemoglobin (g/L) & 132 & $78.1(35.6)$ & $79.5(56,97)$ & $110-165$ \\
\hline Haemoglobin < $110 \mathrm{~g} / \mathrm{L}$ & & $116(87.9 \%)$ & & \\
\hline Microcytic (MCV < 80) & & $38(32.8 \%)$ & & \\
\hline Normocytic (MCV 80-100) & & 75 (64.7\%) & & \\
\hline Macrocytic (MCV > 100) & & $3(2.6 \%)$ & & \\
\hline Haemoglobin < $70 \mathrm{~g} / \mathrm{L}$ & & $53(40.2 \%)$ & & \\
\hline Hematocrit (\%) & 127 & $24.2(7.7)$ & $24.7(19.2,30)$ & $35-50$ \\
\hline Hematocrit <33\% & & $109(85.8 \%)$ & & \\
\hline Hematocrit $<25 \%$ & & $64(50.4 \%)$ & & \\
\hline White cell count $\left(\times 10^{\wedge} 9 / L\right)$ & 131 & $11.9(8.1)$ & $11.2(5.3,16.9)$ & $3.5-10.0$ \\
\hline White cell count > 25 (×10^9/L) & & $8(6.1 \%)$ & & \\
\hline Lymphocyte count $(\times 10 \wedge 9 / L)$ & 122 & $2.6(2.4)$ & $1.9(1,3)$ & $1.2-3.2$ \\
\hline Lymphocyte count < $1(\times 10 \wedge 9 / L)$ & & $26(21.3 \%)$ & & \\
\hline $\begin{array}{l}\text { Differential white cell count (monocytes) } \\
(\times 10 \wedge 9 / \mathrm{L})\end{array}$ & 100 & $1.8(1.8)$ & $1.3(0.6,2.2)$ & $0.3-0.8$ \\
\hline $\begin{array}{l}\text { Differential white cell count } \\
\text { (granulocytes) }\left(\times 10^{\wedge} 9 / \mathrm{L}\right)\end{array}$ & 100 & $8.7(5.6)$ & $7.7(5.1,11.5)$ & $1.2-6.8$ \\
\hline Platelet count $(\times 10 \wedge 9 / L)$ & 130 & $155.2(101.7)$ & $137(86,208)$ & $150-390$ \\
\hline Platelet count < $100(\times 10 \wedge 9 / L)$ & & $41(31.5 \%)$ & & \\
\hline Platelet count < $50(\times 10 \wedge 9 / L)$ & & $17(13.1 \%)$ & & \\
\hline \multicolumn{5}{|l|}{ Coagulation variables } \\
\hline Prothrombin time (PT, seconds) & 137 & $19.0(12.6)$ & $15.2(13.5,18.8)$ & $9.6-12.9$ \\
\hline Normalised prothrombin ratio & 133 & $1.2(0.7)$ & $1.0(0.9,1.2)$ & \\
\hline Normalised prothrombin ratio $>1.2$ & & $29(21.8 \%)$ & & \\
\hline Normalised prothrombin ratio > 1.5 & & $16(12.0 \%)$ & & \\
\hline $\begin{array}{l}\text { Activated partial thromboplastin time } \\
\text { (APTT, seconds) }\end{array}$ & 133 & $35.9(22.9)$ & $30.4(27.1,35.6)$ & \\
\hline Thrombin time (TT, seconds) & 124 & $13.1(12.5)$ & $10.4(9.1,12.6)$ & \\
\hline Normalised thrombin ratio & 124 & $0.9(0.9)$ & $0.7(0.6,0.9)$ & \\
\hline Fibrinogen (g/L) & 136 & $8.4(6.6)$ & $6.6(3.2,12.3)$ & \\
\hline Fibrinogen $(<1 \mathrm{~g} / \mathrm{L})$ & & $4(2.9 \%)$ & & \\
\hline Fibrinogen $(<2 \mathrm{~g} / \mathrm{L})$ & & $16(11.8 \%)$ & & \\
\hline Fibrinogen $(<4 \mathrm{~g} / \mathrm{L})$ & & $45(33.1 \%)$ & & \\
\hline D-Dimer (mg/L) & 119 & $8.6(8.2)$ & $5.7(2.3,13.5)$ & \\
\hline \multicolumn{5}{|l|}{$\begin{array}{l}\text { Thromboelastometry (ROTEM }{ }^{\circledR} \text { EXTEM) } \\
\text { variables }\end{array}$} \\
\hline Clotting time ( $C T$, seconds) & 151 & $127.4(336.9)$ & $54(45,72)$ & $34-66$ \\
\hline Amplitude at 5 mins (A5, mm) & 146 & $42.1(15.8)$ & $47(35,53)$ & \\
\hline $\mathrm{A} 5<40 \mathrm{~mm}$ & & 49 (33.6\%) & & \\
\hline Amplitude at 10 mins (A10, mm) & 149 & $51.6(17.5)$ & $58(47,63)$ & $44-73$ \\
\hline Maximum clot firmness (MCF, mm) & 146 & $59.3(17.5)$ & $65(56,70)$ & $55-78$ \\
\hline Clot lysis at $30 \mathrm{~min}(\mathrm{~L} \mid 30, \%)$ & 145 & $98.0(10.8)$ & $100(100,100)$ & \\
\hline Clot lysis at $60 \mathrm{~min}($ LI60, \%) & 101 & $93.3(10.1)$ & $96(92,99)$ & \\
\hline
\end{tabular}


Table 2 Haematological parameters of trial participants at baseline ( $N=167)$ (Continued)

\begin{tabular}{|c|c|c|c|c|}
\hline & $n^{a}$ & Mean (SD) / Count (\%) & $\begin{array}{l}\text { Median (25th, 75th } \\
\text { centile range) }\end{array}$ & Normal range \\
\hline Maximum Lysis (ML, \%) & 150 & $14.7(20.4)$ & $9(4,15)$ & $0-44$ \\
\hline$M L>15 \%$ & & $35(23.3 \%)$ & & \\
\hline \multicolumn{5}{|c|}{ Thromboelastometry (ROTEM ${ }^{\circledast}$ APTEM) variables } \\
\hline Clotting time ( $C T$, seconds) & 152 & $245.2(882.3)$ & $58(46,81)$ & $31-71$ \\
\hline Amplitude at 5 mins (A5, mm) & 143 & $44.0(15.2)$ & $48(35,54)$ & \\
\hline $\mathrm{A} 5<40 \mathrm{~mm}$ & & $49(33.6 \%)$ & & \\
\hline Amplitude at 10 mins (A10, mm) & 147 & $52.9(16.8)$ & $59(46,64)$ & $43-72$ \\
\hline Maximum clot firmness (MCF, mm) & 144 & $61.4(15.6)$ & $67(58,71)$ & $56-78$ \\
\hline Maximum Lysis (ML, \%) & 147 & $5.9(5.7)$ & $5(2,8)$ & $0-14$ \\
\hline
\end{tabular}

iron deficiency [21]. Women with antenatal anaemia may have an increased risk of $\mathrm{PPH}$ and an increased risk of severe anaemia after delivery $[22,23]$.

One third of women was thrombocytopenic and many were severely thrombocytopenic. This also contrasts with studies in high income countries in which thrombocytopenia is relatively uncommon [24]. The low platelet counts (in the context of the relatively well preserved coagulation factors) may explain why so many women had an EXTEM A5 < $40 \mathrm{~mm}$ since EXTEM A5 values are influenced by platelet and fibrinogen levels. Further studies are needed to assess the FIBTEM and EXTEM A5 levels in similar populations to differentiate the extent to which low platelet and/or fibrinogen levels impact on PPH progression. Several studies have shown that a low A5 using ROTEM FIBTEM measured during the early phase of bleeding is associated with an increased risk of severe $\mathrm{PPH}$ [25].

Our study has several weaknesses. Because we did not collect blood samples prior to PPH onset, we cannot determine whether the abnormal haematological values (anaemia and thrombocytopenia) observed in this study are a cause or consequence of the bleeding. Due to technical problems with either blood samples or measurement instruments, the number of patients with available data was less than the number enrolled. We did not compare our results with a control group of women who did not experience PPH. Although the women in our study were a sample $(54 \%)$ of all those recruited into the WOMAN trial at University College Hospital, we do not believe they were selected based on bleeding severity. The mean blood loss among the 167 women who were included was similar to that for the 142 women enrolled in the Woman trial but not included in this ROTEM study [1530 ml (SD) 897 for the included women versus 1548 (SD) 810] in women not included in the ROTEM study]. Their systolic blood pressures at baseline were also similar $[110 \mathrm{mmHg}$ (27) among included women versus 103 (33) in women who were not included]. It is possible that the reason for the high prevalence of coagulopathy found in our study is that our cohort had more severe PPH than studies in high income settings.

\section{Conclusions}

Based on findings from a convenience sample of women who delivered in a teaching hospital in Nigeria, hyper-
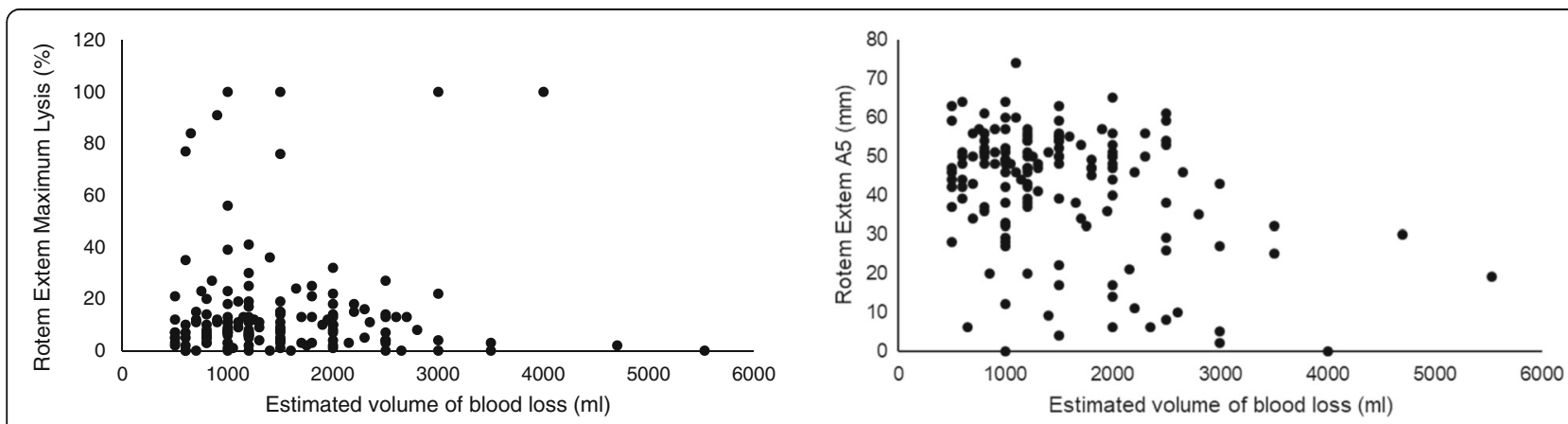

Fig. 3 Scatterplot of the relationship between estimated blood loss and ROTEM ML and A5 
fibrinolysis occurs in nearly $25 \%$ of women with $\mathrm{PPH}$. Further studies into the pathophysiological mechanisms for hyper-fibrinolysis should help us to identify better treatment strategies for women with $\mathrm{PPH}$.

\begin{abstract}
Abbreviations
A5: Clot amplitude (firmness) at five minutes; aPTT: Activated partial thromboplastin time; EDTA: Ethylene diamine triacetic acid; ETAC: Effect of tranexamic acid on coagulation sub-study of woman trial.; EXTEM: Extrinsic screening test on ROTEM; g/L: Grams per litre; HIV: Human immunodeficiency virus; INTEM: Intrinsic screening test on ROTEM; L: Litre; LSHTM: London school of hygiene and tropical medicine; MCV: Mean corpuscular volume; ML: Maximum Lysis; $\mathrm{mL}$ : Millilitre; mmHg: Millimetre of mercury; mol/L: Moles per litre; NAFDAC: National agency for food \& drug administration and control; PAl-1: Plasminogen activator inhibitors; PPH: Postpartum haemorrhage; PT: Prothrombin time; QC: Quality control; ROTEM: Rotational thromboelastometry; t-PA: Tissue plasminogen activator; WOMAN Trial: World maternal anti-fibrinolytic trial
\end{abstract}

\section{Funding}

London School of Hygiene and Tropical Medicine, UK Department of Health, Wellcome Trust, Bill \& Melinda Gates Foundation funded the WOMAN trial. An educational grant, equipment and consumables for ROTEM analysis was provided by tem innovations GmbH, M.-Kollar-Str. 13-15, 81829 Munich, Germany to LSHTM and utilised fully at the university college hospital, Ibadan. The funders had no role in the design of the study and collection, analysis, and interpretation of data or in writing the manuscript.

\section{Availability of data and materials}

Data is available from $\mathrm{HS}$ and IR.

\section{Authors' contributions}

IR and HS conceived the study, contributed data cleaning, statistical analysis and writing of the manuscript. BK contributed to protocol development and had overall responsibility for the study at the trial site and review of the manuscript. OO contributed to protocol development and is the site principal investigator for WOMAN trial and review of the manuscript. MK contributed to the protocol development and was responsible for overseeing laboratory tests, laboratory standard operating procedures and staff training and review of the manuscript. $A B$ contributed to protocol development and was responsible for data transfer and review of the manuscript. OO contributed to the protocol development, development of the standard operating procedures and was responsible for participant recruitment and review of the manuscript. CA contributed to the protocol development and was responsible for participant recruitment and review of the manuscript. TK contributed to the protocol development and was responsible for routine laboratory tests and review of the manuscript. BH contributed to data cleaning and writing of the manuscript. SH conducted the statistical analysis and contributed to the writing of the manuscript. TO was responsible for overseeing laboratory tests, laboratory standard operating procedures and staff training and review of the manuscript. All authors have read and approved the final version of the manuscript.

\section{Ethics approval and consent to participate}

Approvals to conduct this study were obtained from the Ethics Committees of London School of Hygiene and Tropical Medicine and the University of Ibadan \& University College Hospital Ethics Committee. Regulatory approval was obtained from the Nigerian National Agency for Food and Drug Administration and Control (NAFDAC). The study was undertaken according to ICH-GCP guidelines. The consent procedures is detailed in the WOMAN Trial protocol [22]. Briefly, we obtained written consent from a patient if their physical and mental capacity allowed. If a patient could not give written consent, we obtained proxy consent from a relative or representative. If a proxy was unavailable, then if local regulation allows, we deferred or waived consent. In this situation, we informed the patient about the trial as soon as possible, and obtained written consent to use the data. The London School of Hygiene \& Tropical Medicine is the sponsor.

\section{Competing interests}

The authors declare that they have no competing interests.

\section{Publisher's Note}

Springer Nature remains neutral with regard to jurisdictional claims in published maps and institutional affiliations.

\section{Author details}

${ }^{1}$ Clinical Trials Unit, London School of Hygiene and Tropical Medicine, Keppel Street, London WC1E 7HT, UK. ${ }^{2}$ Department of Obstetrics \& Gynaecology, National Institute of Maternal and Child Health, College of Medicine, University of Ibadan, Orita-Mefa, Ibadan, Nigeria. ${ }^{3}$ Department of Chemical Pathology, College of Medicine, University of Ibadan, Orita-Mefa, Ibadan, Nigeria. ${ }^{4}$ Department of Obstetrics \& Gynaecology, College of Medicine, University of Ibadan, Orita-Mefa, Ibadan, Nigeria. ${ }^{5}$ Department of Haematology, College of Medicine, University of Ibadan, Orita-Mefa, Ibadan, Nigeria. ${ }^{6}$ Thrombosis \& Haemophilia Centre, Guy's \& St Thomas' Trust, St Thomas' Hospital, Lambeth Palace Road, London, UK.

Received: 31 January 2018 Accepted: 30 April 2018

Published online: 09 May 2018

\section{References}

1. CRASH-2 trial collaborators, Shakur H, Roberts I, Bautista R, Caballero J, Coats T, et al. Effects of tranexamic acid on death, vascular occlusive events, and blood transfusion in trauma patients with significant haemorrhage (CRASH-2): a randomised, placebo-controlled trial. Lancet. 2010;376(9734):23-32.

2. CRASH-2 collaborators, Roberts I, Shakur H, Afolabi A, Brohi K, Coats T, et al. The importance of early treatment with tranexamic acid in bleeding trauma patients: an exploratory analysis of the CRASH-2 randomised controlled trial. Lancet. 2011;377(9771):1096-101.

3. Roberts I, Prieto-Merino D, Manno D. Mechanism of action of tranexamic acid in bleeding trauma patients: an exploratory analysis of data from the CRASH-2 trial. Crit Care. 2014;18:685.

4. Raza I, Davenport R, Rourke C, Platton S, Manson J, Spoors C, Khan S, De'ath H, Allard S, Hart D, John Pasi K, Hunt BJ, Stanworth S, Maccallum P, Brohi K. The incidence and magnitude of fibrinolytic activation in trauma patients. J Thromb Haemost. 2013;11(2):307-14

5. Chapman MP, Moore EE, Moore HB, Gonzalez E, Gamboni F, Chandler JG, Mitra S, Ghasabyan A, Chin TL, Sauaia A, Banerjee A, Silliman CC. Overwhelming tPA release, not PAl-1 degradation, is responsible for hyperfibrinolysis in severely injured trauma patients. J Trauma Acute Care Surg. 2016;80:16-25.

6. Cap A, Hunt BJ. The pathogenesis of traumatic coagulopathy. Anaesthesia. 2015;70(Suppl 1):e96-101.

7. The WOMAN Trial Collaborators. Effect of early administration of tranexamic acid on mortality, hysterectomy, other morbidities in women with postpartum haemorrhage (the WOMAN trial): a randomised, placebocontrolled trial. Lancet. 2017;389(10084):2105-16.

8. Wikkelsø AJ, Edwards HM, Afshari A, Stensballe J, Langhoff-Roos J, Albrechtsen C, Ekelund K, Hanke G, Secher EL, Sharif HF, Pedersen LM, Troelstrup A, Lauenborg J, Mitchell AU, Fuhrmann L, Svare J, Madsen MG, Bødker B, Møller AM, FIB-PPH trial group. Pre-emptive treatment with fibrinogen concentrate for postpartum haemorrhage: randomized controlled trial. Br J Anaesth. 2015;114:623-33.

9. World Health Organization (WHO). The prevalence of Anaemia in women: a tabulation of available information. Geneva: WHO; 1992 WHO/MCH/MSM/92.2

10. Brohi K, Singh J, Heron M, Coats T. Acute traumatic coagulopathy. J Trauma. 2003:54:1127-30.

11. Hagemo JS, Christiaans SC, Stanworth SJ, et al. Detection of acute traumatic coagulopathy and massive transfusion requirements by means of rotational thromboelastometry: an international prospective validation study. Crit Care 2015;19(1):97.

12. de Lange $N M$, van Rheeneen-Flach $L E$, Lance $M D$, Mooyman $L$, et al. Peri-partum reference ranges for ROTEM ${ }^{\circledast}$ thromboelastometry. $\mathrm{Br} \mathrm{J}$ Anaesth. 2014;112(5):852-9.

13. Ronsmans C, Graham WJ. Lancet maternal survival series steering group: maternal mortality: who, when, where, and why. Lancet. 2006;368(9542):1189-200.

14. Solomon C, Collis R, Collins P. Haemostatic monitoring during postpartum haemorrhage and implications for management. Br J Anaesth. 2012; 109(6):851-63.

15. Erhabor O, Isaac I, Muhammad A, Abdulrahman Y, Ezimah A, Adias T. Some hemostatis parameters in women with obstetric haemorrhage in Sokoto, Nigeria. Int J Womens Health. 2013;5:285-91. 
16. Mackinnon S, Walker ID, Davidson JF, Walker JJ. Plasma fibrinolysis during and after normal childbirth. Br J Haematol. 1987;65:339-42.

17. Bremer HA, Brommer EJP, Wallenburg HCS. Effects of labour and delivery on fibrinolysis. Eur J Ob Gynaecol Repro Biol. 1994;55:163-8.

18. Ducloy-Bouthors AS, Duhamel A, Kipnis E, Tournoys A, Prado-Dupont A, Elkalioubie A, Jeanpierre E, Debize G, Peynaud-Debayle E, DeProst D, Huissoud C, Rauch A, Susen S. Postpartum haemorrhage related early increase in D-dimers is inhibited by tranexamic acid: haemostasis parameters of a randomized controlled open labelled trial. $\mathrm{Br} J$ Anaesth 2016;116:641-8.

19. Okwesili A, Ibrahim $\mathrm{K}$, Nnadi $\mathrm{D}$, Barnabas $B$, Abdulrahaman $Y$, Buhari $\mathrm{H}$, Udomah F, Imoru M, Egenti B, Erhabor O. Fibrinogen levels among pregnant women of African descent in Sokoto north western Nigeria. Front Biomed Sci. 2016;1 (2):7-11.

20. Madden $\mathrm{E}$, Lee $\mathrm{G}$, Kotler DP, et al. Association of Antiretroviral Therapy with fibrinogen levels in HIV infection. AIDS. 2008;22(6):707-15.

21. Olatunbosun O, Abasiattai A, Bassey E, James R, Ibanga G, Morgan A. Prevalence of anaemia among pregnant women at booking in the University of Uyo Teaching Hospital. Uyo: Biomed Research International; 2014. Article ID: 849080

22. Nair M, Choudhry MK, Choudhry SS, Kakoty SD, Sarma UC, Webster P, et al. Association between maternal anaemia and pregnancy outcome: a cohort study in Assam, India. BMJ Global Health. 2016;1:e00026.

23. Butwick A, Walsh E, Kuzniewicz M, Li S, Escobar G. Patterns and predictors of severe postpartum anemia after cesarean section. Transfusion. 2017;57:36-44.

24. Jones RM, de Lloyd L, Kealaher EJ, Lilley GJ, Precious E, Burckett st Laurent D, Hamlyn V, Collis RE, Collins PW, collaborators. Platelet count and transfusion requirements during moderate or severe postpartum haemorrhage. Anaesthesia. 2016;71:648-56.

25. Collins PW, Lilley G, Bruynseels D, et al. Fibrin-based clot formation as an early and rapid biomarker for progression of postpartum hemorrhage: a prospective study. Blood. 2014;124:1727-36.

\section{Ready to submit your research? Choose BMC and benefit from:}

- fast, convenient online submission

- thorough peer review by experienced researchers in your field

- rapid publication on acceptance

- support for research data, including large and complex data types

- gold Open Access which fosters wider collaboration and increased citations

- maximum visibility for your research: over $100 \mathrm{M}$ website views per year 